\section{Could mannequins menstruate?}

\author{
Minna Rintala, Pertti Mustajoki
}

Women should have at least $17 \%$ of their weight as fat in order to have menarche and $22 \%$ in order to have regular cycles.' This fat contains easily mobilisable energy which provides nourishment during pregnancy and lactation.

Mannequins that display clothes in fashion shops may influence women's perception of ideal weight. We investigated the changing shape of display figures over time and determined whether women of their size would have enough fat for menstruation.

\section{Subjects, methods, and results}

Six old mannequins (from the 1920s, '30s, '50s, and '60s) in the Helsinki City Museum and modern dummies imported from three countries (Italy, Japan, and Malaysia) were investigated. Height and various circumferences were measured on every mannequin.

Body fat was calculated according to the formula: body fat $(\mathrm{kg})=1.176 \mathrm{arm}$ circumference +0.635 thigh circumference $-44 \cdot 255 .^{2}$ Amount of fat was expressed as $\mathrm{kg}$ not as percentage of body weight because formulas for percentages of fat would need body weight or density, both of which would have been inaccurate estimations. Body fat of hypothetical women of same height as the dummies was estimated for two classes of body mass index, $20 \mathrm{~kg} / \mathrm{m}^{2}$ and $25 \mathrm{~kg} / \mathrm{m}^{2}$ according to the criteria of Scott and Johnston. ${ }^{3}$

The same anthropometric measurements and calculations were made on six average sized female medical students aged 20-30 years. In addition their subscapular, abdominal, and tricep skin folds were measured. Amount of body weight as fat was calculated from circumferences as in the dummies ${ }^{2}$ and

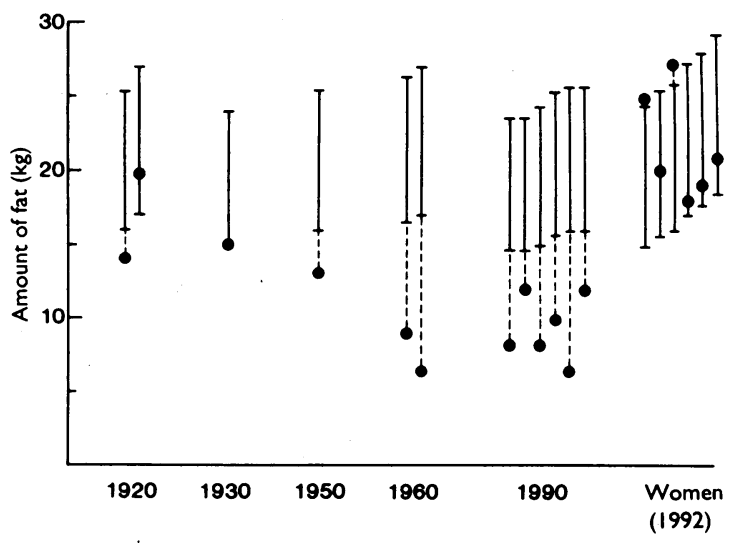

Calculated amount of fat of mannequins from five decades and young women are shown as solid circles (•). The vertical lines give estimated amount of fat in hypothetical women of same height and with body mass indexes $20-25 \mathrm{~kg} / \mathrm{m}^{2}$

from skin folds, taking the mean result obtained by four different formulas. ${ }^{24}$

Arm, hip, and thigh circumferences of the modern display figures were $2-3 \mathrm{~cm}, 8 \mathrm{~cm}$, and $4-5 \mathrm{~cm}$ less, respectively, than those of figures from before the second world war. Modern display figures and female medical students respectively had a mean height of 169 (range 166-172) $\mathrm{cm}$ and $175(168-182) \mathrm{cm}$; arm circumference, $23(21-24) \mathrm{cm}$ and $28(26-31) \mathrm{cm}$; hip circumference, $79(73-82) \mathrm{cm}$ and $93(87-100) \mathrm{cm}$; thigh circumference, $43(41-44) \mathrm{cm}$ and $53(51-57) \mathrm{cm}$.

Our figure shows that the calculated amount of fat of the display figures was mostly in the normal range before the 1950s but has been considerably less since
Mannequins through the decades-(left to right) 1920s, 1930s, 1950s, 1960s, 1990s (Helsinki City Museum)
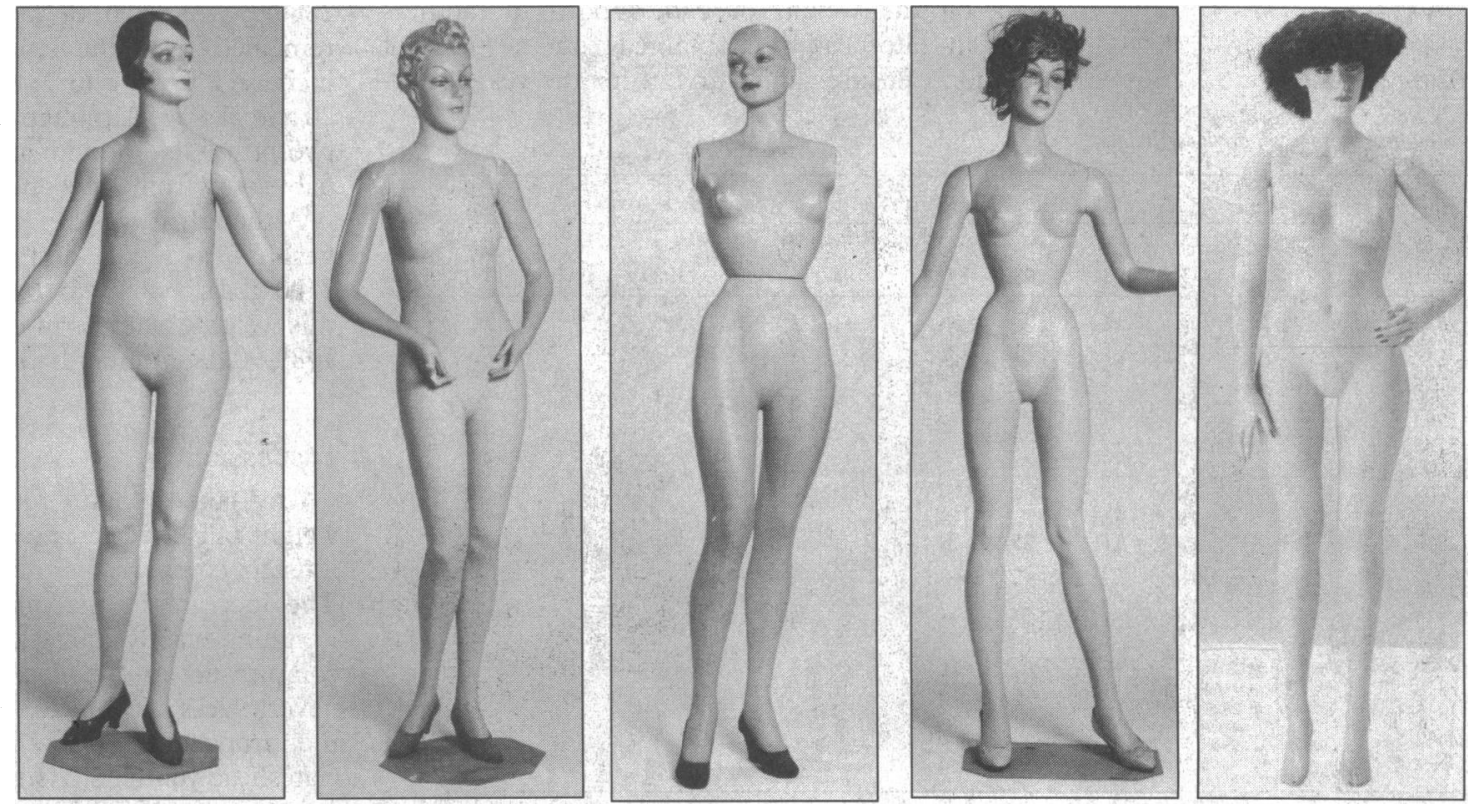
then. Percentages of fat in the women students varied from $23 \cdot 0 \%$ to $32 \cdot 2 \%$ when calculated from circumferences and were comparable $(21.6 \%$ to $31.5 \%)$ when calculated from skin fold measurements.

\section{Comment}

Our results show that display figures have become thinner with time and their proportions now differ considerably from those of normal young women. The structural changes seen in display figures during this century have led to a considerable reduction in the proportion of body weight calculated to be fat. A woman with the shape of a modern mannequin would probably not menstruate.

We often take a smiling or even horrified attitude towards the fashion phenomena of foreign cultures, but in our own society we get accustomed to the whims of fashion from early childhood. A woman with the proportions of a Barbie doll would be even thinner than the modern display figure (unpublished observations). Many of the phenomena of fashion are harmless, but the trend of extreme thinness is not without dangers. Most girls in industrialised countries are concerned with their body shape and practise occasional dieting. ${ }^{5}$
Although most of them survive without major problems, persistent dissatisfaction with one's own body may cause unnecessary concern and lessen happiness. In some girls this may proceed to the development of an eating disorder.

Why is the idealised weight so low? From the history of fashion we can see that during times of scarcity wide skirts with plenty of material were fashionable. When plenty of material was available the skirts were short and narrow. Similarly, being fat was socially desirable in times when there was a shortage of food. Now, in societies with excess food the ideal body shape is extremely thin. It seems that things difficult to achieve are pursued.

1 Frisch RE. Fatness, menarche and female fertility. Perspect Biol Med 1985;28:611-33.

Steinkamp RC, Cohen NL, Gaffey WR, McKey T, Bron G, Siri WE, et al. Measures of body fat and related factors in normal adults. II. A simple clinical method to estimate body fat and lean body mass. F Chron Dis 1965;18: 1291-307

Scott EC, Johnston FE. Critical fat, menarche, and the maintenance of menstrual cycles. F Adolesc Health Care 1982;2:249-60.

Smith DP, Boyce RW. Prediction of body density and lean body weight in females 25 to 37 years old. Am $\mathcal{A}$ Clin Nutr 1977;30:560-4

5 Patton GC, Johnson-Sabine E, Wood K, Mann AH, Wakeling A. Abnormal eating attitudes in London schoolgirls - a prospective epidemiological study: outcome at twelve months. Psychol Med 1990;20:383-94.

\section{How to gain weight by looking up}

\section{A J Newens, S N Jarvis, R George}

Low birth weight is generally defined as births "less than $2500 \mathrm{~g}$ (up to and including $2499 \mathrm{~g}$ )" and is associated with increased perinatal mortality risk. ${ }^{2}$ An alternative criterion for low birth weight (less than $2800 \mathrm{~g}$ ) was used by Townsend $e t a l$ as part of a health index for districts in the Northern health region of England.

During a study of perinatal mortality in Gateshead we examined the recording of birth weight over time to explain a fall from $7 \cdot 8 \%$ in 1982 to $5 \cdot 9 \%$ (below the average in Northern region) in 1990 in the proportion of babies weighing less than $2500 \mathrm{~g}$ at birth. There was less change $(14 \cdot 8-14 \cdot 1 \%)$ when $2800 \mathrm{~g}$ was used as a criterion.

\section{Method and results}

Data on the weight of babies born to mothers resident in Gateshead were obtained from the Office of Population Censuses and Surveys for the years 1982-

BMF 1992;305:1576-7

Weights recorded on birth certificates

No of births recorded by year

\begin{tabular}{|c|c|c|c|c|c|c|c|c|c|c|c|}
\hline $\begin{array}{l}\text { Weight } \\
\text { (grams) }\end{array}$ & 1982 & 1983 & 1984 & 1985 & 1986 & 1987 & 1988 & 1989 & 1990 & 1991 & Total \\
\hline 2780 & 22 & 21 & 18 & 26 & 22 & 11 & 22 & 23 & 27 & 23 & 215 \\
\hline $\begin{array}{l}2780 \\
2785\end{array}$ & & $\begin{array}{r}21 \\
1\end{array}$ & & $\begin{array}{r}20 \\
1\end{array}$ & 22 & 11 & 22 & & & & 2 \\
\hline 2788 & & & 1 & & & & & & & & 1 \\
\hline 2790 & 2 & 5 & 3 & & 1 & & & 1 & 1 & & 13 \\
\hline 2792 & & & & & $i$ & & & & & & 1 \\
\hline 2795 & 1 & & & 2 & & & & & & & 3 \\
\hline 2800 & 22 & 20 & 15 & 2 & 1 & 4 & 8 & 5 & 1 & 1 & 79 \\
\hline 2805 & & 1 & & 1 & $i$ & & & & & & 3 \\
\hline 2807 & 3 & 1 & 1 & & 1 & 1 & 1 & 1 & 2 & & 11 \\
\hline 2810 & 3 & $i$ & 11 & 25 & 24 & 21 & 16 & 21 & 24 & 20 & 166 \\
\hline 2815 & 2 & & & & & 1 & & & & 1 & 4 \\
\hline 2820 & 23 & 15 & 20 & 2 & 1 & 3 & 4 & 3 & 2 & 2 & 75 \\
\hline 2824 & & & 1 & & & & & & & & 1 \\
\hline 2825 & & 1 & 1 & & & & & & 1 & 1 & 4 \\
\hline 2826 & & 1 & & & & & & & & & l \\
\hline 2830 & 1 & & 1 & 2 & 1 & 1 & 1 & 1 & 1 & 3 & 12 \\
\hline 2835 & 4 & 3 & 3 & 4 & 2 & 3 & 2 & 1 & 3 & 6 & 31 \\
\hline 2840 & 2 & 4 & 8 & 43 & 16 & 26 & 31 & 35 & 22 & 20 & 207 \\
\hline 2845 & & & & & & 1 & & 1 & & & 2 \\
\hline
\end{tabular}

These data were derived from birth notification documents completed at the time of birth, in grams, by a midwife and subsequently transferred to the registrar of births. In the Gateshead maternity unit, which accounted for two thirds of local births, the babies were weighed on the same analogue scales calibrated in $20 \mathrm{~g}$ and 1 ounce intervals throughout the study period. In the two Newcastle hospitals that deliver most other Gateshead babies both analogue and digital scales were used. Of the 26131 birth registrations, $0 \cdot 3 \%$ had birth weight missing.

Rounding of most weights, in $20 \mathrm{~g}$ or $30 \mathrm{~g}$ increments, was found throughout the study period. The pattern of rounding changed, however, over the period 1983 to 1985 , and there was a tendency for weights to be $10 \mathrm{~g}$ or $20 \mathrm{~g}$ higher after 1985 . As an example, the distribution of birth weights between $2770 \mathrm{~g}$ and $2850 \mathrm{~g}$ is shown in the table. The weight $2780 \mathrm{~g}$ remained over the study period, whereas $2800 \mathrm{~g}$ increased by $10 \mathrm{~g}$ to $2810 \mathrm{~g}$, and $2820 \mathrm{~g}$ increased by $20 \mathrm{~g}$ to $2840 \mathrm{~g}$. Although rounding was noted in at least two hospitals, individual maternity units were identifiable only from 1989 onwards.

Although it was not as clear cut as at higher birth weights, a degree of readjustment was apparent at $2500 \mathrm{~g}$. In 1982-3 six births were recorded at exactly this weight, whereas in 1985-6 the number was 18 . By 1989-90 the number had risen further to 30 .

\section{Discussion}

Any cut off point for the definition of low birth weight calls for accurate recording of such information if useful comparisons are to be made between districts. The increase in the number of babies recorded as weighing exactly $2500 \mathrm{~g}$ after $1982-3$, although small in comparison to the overall number of births, may nevertheless account for a part of the apparent fall in the proportion of low birthweight babies born to Gateshead mothers. As there was no upward revision 